\title{
Whitepaper on Uncertainty Quantification for MPACT
}

\author{
Revision 0 \\ December 17, 2015
}

Mark L. Williams

Approved for public release.

Distribution is unlimited.
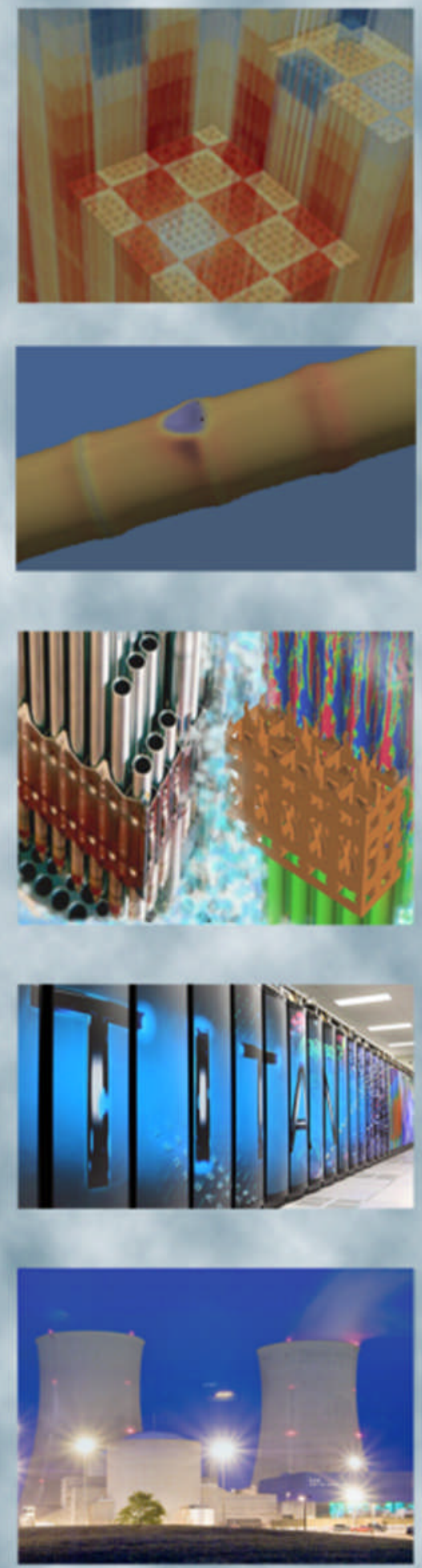


\section{REVISION LOG}

\begin{tabular}{|c|c|c|l|}
\hline Revision & Date & Affected Pages & \multicolumn{1}{c|}{ Revision Description } \\
\hline 0 & $12 / 17 / 2015$ & All & Initial version \\
\hline & & & \\
\hline & & & \\
\hline & & & \\
\hline
\end{tabular}

Document pages that are:

Export Controlled None

IP/Proprietary/NDA Controlled None

Sensitive Controlled None

Unlimited $\underline{\text { All }}$

\section{Requested Distribution:}

To: N/A

Copy: N/A

\section{Reviewed by:}

Date:

Reviewer: Kevin Clarno 


\section{DOCUMENT AVAILABILITY}

Reports produced after January 1, 1996, are generally available free via US Department of Energy (DOE) SciTech Connect.

Website http://www.osti.gov/scitech/

Reports produced before January 1, 1996, may be purchased by members of the public from the following source:

National Technical Information Service

5285 Port Royal Road

Springfield, VA 22161

Telephone 703-605-6000 (1-800-553-6847)

TDD 703-487-4639

Fax 703-605-6900

E-mail info@ntis.gov

Website http://www.ntis.gov/help/ordermethods.aspx

Reports are available to DOE employees, DOE contractors, Energy Technology Data Exchange representatives, and International Nuclear Information System representatives from the following source:

Office of Scientific and Technical Information

PO Box 62

Oak Ridge, TN 37831

Telephone 865-576-8401

Fax 865-576-5728

E-mail reports@osti.gov

Website http://www.osti.gov/contact.html

This report was prepared as an account of work sponsored by an agency of the United States Government. Neither the United States Government nor any agency thereof, nor any of their employees, makes any warranty, express or implied, or assumes any legal liability or responsibility for the accuracy, completeness, or usefulness of any information, apparatus, product, or process disclosed, or represents that its use would not infringe privately owned rights. Reference herein to any specific commercial product, process, or service by trade name, trademark, manufacturer, or otherwise, does not necessarily constitute or imply its endorsement, recommendation, or favoring by the United States Government or any agency thereof. The views and opinions of authors expressed herein do not necessarily state or reflect those of the United States Government or any agency thereof. 



\section{INTRODUCTION}

The MPACT code provides the ability to perform high-fidelity deterministic calculations to obtain a wide variety of detailed results for very complex reactor core models. However MPACT currently does not have the capability to propagate the effects of input data uncertainties to provide uncertainties in the calculated results. This white paper discusses a potential method for MPACT uncertainty quantification (UQ) based on stochastic sampling.

Stochastic sampling methods determine the uncertainty in any calculated result by repeated passes through the computational sequence, each with a randomly perturbed sample of all input variables of interest. Because the input data are perturbed prior to the beginning of the computations, this approach requires little or no modification to the underlying computational algorithms. The distributions of the perturbed output values provide mean values, standard deviations, as well as correlation coefficients between various types of results. ORNL has implemented this approach in the SAMPLER module that will be included in the next release of SCALE (version 6.2). SAMPLER can propagate uncertainties in all types of cross sections, fission product yields, and decay data, as well as modeling parameters, for any type of SCALE multigroup (MG) computational sequence. This white paper presents a possible Sampler-based methodology for performing uncertainty calculations with MPACT to address cross sections uncertainties. Other types of uncertainties (transmutation and modeling parameters) can be addressed in a future whitepaper. This methodology is only for UQ and does not provide sensitivity coefficients. 


\section{POTENTIAL UQ METHODOLOGY FOR IMPACT}

The proposed approach is to pre-compute 500-1000 randomly perturbed MPACT libraries by varying the multigroup (MG) and continuous energy (CE) data used by the processing codes that generate the libraries. UQ analysis would then just be a matter of running MPACT for the desired number of samples (i.e., libraries) and performing statistical analysis on the output distributions. This can be done using Sampler, or another Sampler-like wrapper code could be developed explicitly for MPACT.

The first step in this procedure is create a new sequence for AMPX that combines all the current processing modules that generate self-shielding data, such as IR lambda values, homogeneous and heterogeneous f-factors, and subgroup parameters. This requires developing a driver routine that reads user input options, loads existing MG and CE libraries into memory using SCALE resource routines, and calls APIs for the processing modules to compute self-shielding data for the specified nuclides. Some modifications to the individual modules are also likely necessary so they fit together logically. The shaded box in Fig. 1 indicates this sequence. Aside from its utility for producing perturbed MPACT libraries, the sequence is very desirable for the standard AMPX library processing because it simplifies the overall procedure by reducing the number of independent steps, and improves maintainability. A single run would accomplish what 3 or 4 independent runs currently do. The sequence execution could probably be completed in a day. After developing this new sequence, perturbed MPACT (or AMPX) libraries can be produced by executing Clairol-plus and Crawdad-plus prior to running the sequence for each desired sample, as indicated in Figure 1. Each perturbed library can be processed independently, so these runs can be done simultaneously on different computing nodes. Thus the entire set of perturbed libraries could probably be produced over a single weekend, if not a single day. The perturbed libraries only need to be processed once and saved for the future UQ analysis.

Figure 2 shows the MPACT UQ calculation procedure using the pre-generated perturbed libraries inside of a Sample-type wrapper. Sampler is used to load a perturbed library for a given Sample, to scrap the desired responses from the MPACT output, and perform statistical analysis, 


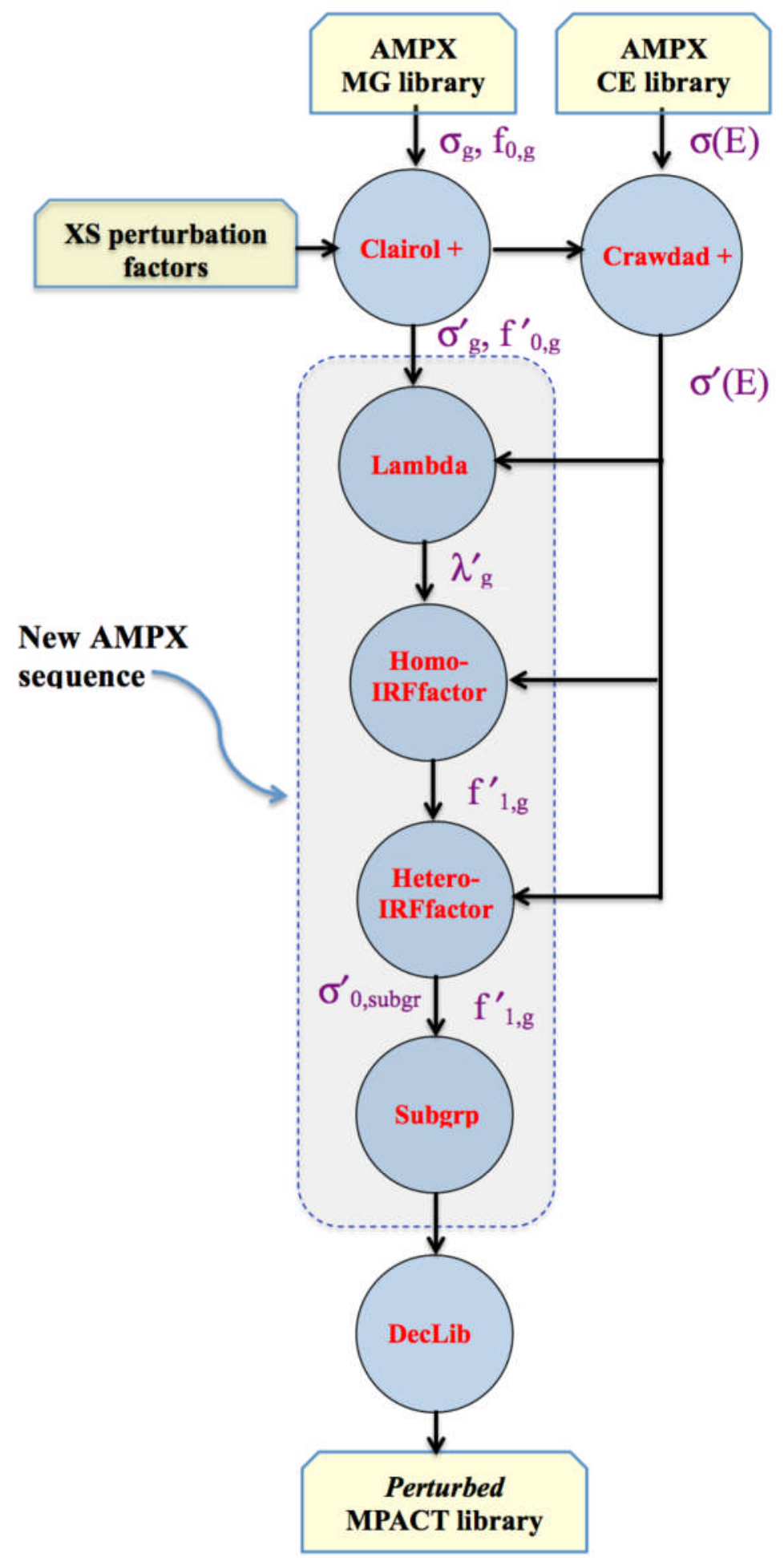

Figure 1. Generation of a Perturbed MPACT Library 


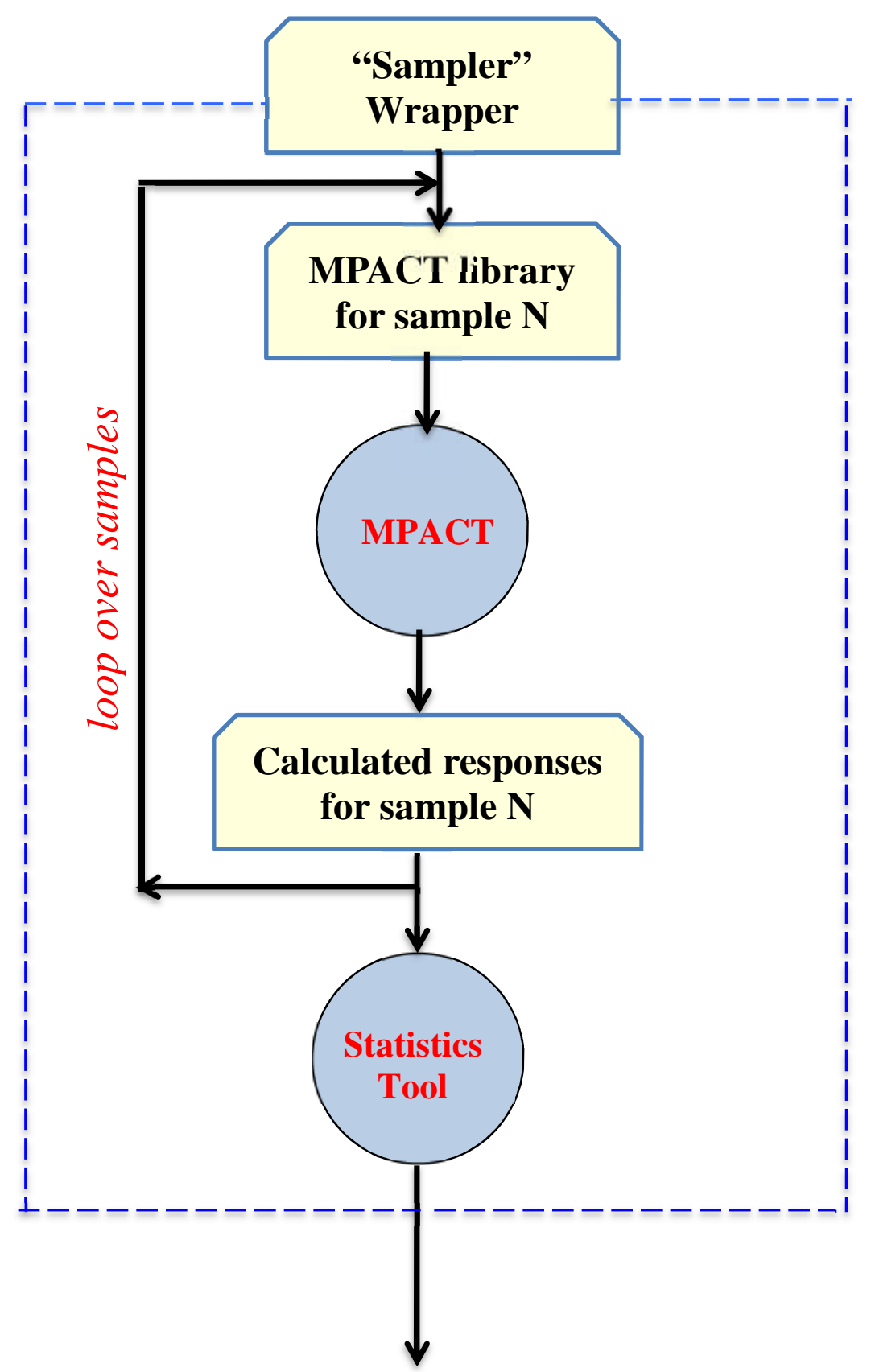

Sampler Output:

standard deviations, correlations, etc.

Figure 2. UQ Analysis with MPACT 


\section{ACKNOWLEDGEMENT}

The author would like to acknowledge Kevin T. Clarno who is the CASL PHI lead for his efforts to review this document in detail and provide valuable comments. 